\title{
OS DESAFIOS DA POLÍTICA SOCIAL NA AMÉRICA LATINA
}

\author{
CHALLENGES OF SOCIAL POLICIES IN LATIN AMERICAS \\ LOS DESAFÍOS DE LA POLÍTICA SOCIAL EN AMÉRICA LATINA
}

Resumo

Este artigo pretende dar uma resposta ao aparente paradoxo existente entre os significativos recursos destinados a programas sociais nos países de América Latina e os relativamente escassos resultados do esforço para a solução dos problemas de pobreza e desigualdade na região. Como chave explicativa desse paradoxo, nossa tese consiste em que, além dos problemas de gestão e de eficácia na aplicação dos recursos, se constata a ausência da dimensão política na aplicação da política social, deficit que se deve em grande parte ao receio expresso pelas autoridades às variadas formas de participação cidadã, apreensão que tende a privilegiar a manutenção da governabilidade e a ordem social em detrimento do envolvimento e da atuação direta dos cidadãos nos assuntos que são de sua competência.

Palavras-chave: América Latina; Política Social; Governabilidade, Democracia, Participação cidadã.

Fernando Marcelo de la Cuadra - fmdelacuadra@gmail.com

Sociologo, Universidade do Chile. Doutor em Ciencias Sociais, Universidade Federal Rural do Rio de Janeiro. Pesquisador da Rede Universitária de Pesquisadores sobre a América Latina (RUPAL) e do Grupo de Trabalho "Mudança ambiental global, mudança climática, movimentos sociais e políticas públicas" do Conselho Latinoamericano de Ciências Sociais (CLACSO)

\section{Artigo submetido no dia 16.08.2013 e aprovado em 09.06.2014}

\section{Abstract}

This article aims to respond to the apparent paradox between the significant resources allocated to social programs in Latin America countries and the relatively meager results of this effort in solving the problems of poverty and inequality in the region. As an explanatory key to this paradox, our thesis is that beyond the problems of management and efficiency in the application of resources, there has been a lack of political dimension in the implementation of social policies, a deficit largely due to fears expressed by the authorities regarding the various forms of citizen participation, a fear which tends to focus on the maintenance of social order and governance, over the involvement of direct action of citizens in matters of their competence.

Keywords: Latin America; Social Policy; Governance; Democracy, Citizen Participation.

\section{Resumen}

El presente artículo pretende dar una respuesta a la aparente paradoja que existe entre los importantes recursos destinados para programas sociales en los países de América Latina y los relativamente escasos resultados de este esfuerzo en la solución de los problemas de pobreza y desigualdad en la región. Como clave explicativa de esța paradoja, nuestra tesis consiste en que más allá de los problemas de gestión y de eficacia en la aplicación de los recursos, se constata una falta de la dimensión política en la aplicación de la politica social, déficit que se debe en gran parte al temor expresado por las autoridades a las variadas formas de participación ciudadana, miedo este que tiende a privilegiar el mantenimiento de la gobernabilidad y al orden social, por sobre la participación y la acción directa de la ciudadanía en los temas que son de su competencia.

Palabras clave: América Latina; Política Social; Gobernabilidad, Democracia, Participación ciudadana. 


\section{A retomada da questão social na América Latina}

Depois da falência demonstrada pela modelo neoliberal ${ }^{1}$ para resolver os entraves do desenvolvimento e melhorar as condições de vida da população latino-americana mais carente por meio de políticas focalizadas e compensatórias, o empenho colocado para a erradicação da pobreza e os debates associados à problemática social têm-se reposicionado num lugar prioritário entre os temas da agenda governamental da ampla maioria dos países da região. Esse propósito resulta ainda mais relevante na medida em que nos últimos anos um número importante de coalizões de esquerda ou "progressistas" foi eleito para conduzir os destinos dos países na América Latina. ${ }^{2}$ Sem prejuízo das diversas tipologias elaboradas para caracterizar os governos que chegaram ao poder recentemente, podemos afirmar que um aspecto em comum a quase todos eles é sua declarada prioridade para resolver a pobreza, a qual continua sendo, sem distinção, a principal causa da frustração e descontento dos habitantes. Com efeito, o aumento da proteção social representa um tema prioritário na agenda das variadas administrações, considerando precisamente a "sensibilidade" de esquerda de um número expressivo de governos, excetuando em rigor os casos do Paraguai, da Colômbia, do Panamá e de Honduras, que se poderiam definir genericamente como pactos de centro-direita.

A ênfase à "questão social" ficou bastante evidente na declaração final da última Cúpula Ibero-americana (XXIII) de Chefes de Estado e de Governo, realizada em 2013 na Cidade de Panamá, em que se explicitou que um dos motivos centrais da reunião consistiu em pensar e elaborar coletivamente os caminhos para empreender ações integradas de luta contra a pobreza e a desigualdade. Num item dessa declaração, estabelece-se o compromisso de todos os governos de:

Promover uma maior coordenação das políticas públicas, nas quais as prioridades sócias estejam no centro do desenho da política econômica dos nossos países para prevenir e mitigar os efeitos nocivos e as múltiplas manifestações e consequências que as crises econômicas e financeiras internacionais têm nos nossos povos e nos nossos Estados (Cúpula Ibero-americana, 2013, p. 2).

Além de revelar os riscos demagógicos incorporados ao discurso político de costume, essa definição constitui uma irrepreensível afirmação de princípios em prol de sociedades mais justas e inclusivas. Ou seja, deixando de lado algumas afirmações que possuem especialmente um impacto propagandístico, ${ }^{3}$ pode-se pensar que a atual conjuntura representa um marco propício para gerar expectativas positivas em torno dos esforços que deveriam realizar tais governos no combate à pobreza e na procura de maior integração social. Esse cenário tem sido fortalecido pelos efeitos nocivos que as políticas neoliberais provocaram em muitos países do hemisfério, tal e como foi constatado em diversos estudos da Comissão Econômica para América Latina (CEPAL, 1990, 2007 e 2013) e do Banco Interamericano de Desenvolvimento (BID).

Por exemplo, atualmente, parte significativa desse debate gira em torno do fortalecimento da integração dos países pela conformação da União Sul-americana de Nações (Unasul). Desde sua fundação, a postura majoritária dos membros da Unasul tem sido dar prioridade aos temas sociais, com a iniciativa específica de criar o "observatório 
social" para fornecer informação mensal precisa sobre os indicadores sociais (pobreza, saúde, educação) de cada um dos 12 países integrantes do bloco, além de permanecer à disposição dos cidadãos.

Essa mudança na orientação da política verbalizada pelas diversas administrações a respeito do protagonismo da cidadania na construção da agenda, assim como na formulação, aplicação, avaliação e seguimento das políticas deve-se à convicção cada vez mais acentuada - e constatada por vários estudos (Cohen, 2005; Jarquín, 2000; Kliksberg, 2000) - de que, sem a participação cidadã, o sucesso dos programas sociais é bastante menor que nos casos onde existe a dita participação. Voltaremos sobre esse aspecto mais adiante.

Um fator relevante na base dessa nova concepção decorre da experiência acumulada pelas Organizações Não Governamentais (ONG) durante os anos 1970 e 1980. Demonstrou-se que as políticas sociais que tiveram sucesso foram executadas em algumas circunstâncias por tais organizações no âmbito da sociedade civil.4 Quer dizer, no contexto de regimes autoritários, caracterizados pela rígida compressão dos gastos sociais e pela diminuição do poder dos sindicatos por meio de reformas laborais decaráter regressivo, oesforço efetuado pelas ONG tinha como finalidade proporcionar principalmente ajuda, serviços e prestações a seus próprios associados, a setores específicos da população e aos grupos desprovidos especialmente afetados pela aplicação das políticas econômicas. Dessa forma, as ações realizadas pela sociedade civil não possuíam a extensão e cobertura necessárias para suprir as graves carências observadas entre os grupos vulneráveis.

O processo de redemocratização iniciado em meados dos anos 1980 não resolveu a problemática social deficitária deixada pelos governos militares. Ao contrário, junto com a recuperação da democracia na maioria dos países latino-americanos, começaram a ser aplicadas políticas sob o comando do paradigma neoliberal, ${ }^{5} \mathrm{em}$ que se redefine o papel do Estado, passando de um Estado "intervencionista" a um Estado mínimo, orientado basicamente para manutenção dos equilíbrios macroeconômicos (fiscal e monetário), proteção da propriedade privada, aplicação da justiça, preservação dos contratos, defesa das fronteiras e políticas compensatórias para os setores em situação de pobreza extrema. As políticas focalizadas para os mais pobres baseiam-se na suposição de que, diante da disciplina fiscal necessária para manter 0 equilíbrio das contas públicas, os governos deveriam restringir o gasto social para aqueles setores da população mais carente ou em situação de maior vulnerabilidade.

Essa nova concepção liberal processou-se a partir da chamada crise fiscal do Estado, que afetou especialmente as políticas sociais, as quais passaram a ser definidas em termos neoassistencialistas, quer dizer, onde os pobres se transformam em beneficiários de um conjunto de ações específicas para mitigar sua condição de privaçãodosmeiosmateriaisimprescindíveis para sobreviver. Nas palavras de Fleury:

... este patrão se caracteriza por uma segmentação das políticas sociais de acordo com o poder aquisitivo de cada grupo, de modo que se desenham sistemas duais de serviços sociais, ou seja, públicos para os pobres e de mercado para quem os pode pagar" (Fleury, 2004, p. 141).

Para tentar contornar essa situação, foi produzido um estímulo oficial a iniciativas "filantrópicas" levadas a cabo 
por agências da mesma sociedade civil que tinham legitimado seu acionar em tempos de ditadura (igrejas, ONG, associações voluntárias), mais outras fundações, corporações e entidades filantrópicas vinculadas a empresas e organismos internacionais, constituindo um conjunto amorfo de entidades que, posteriormente, adquiriram o cunho de Terceiro Setor.

Um desdobramento dessa questão consiste na revogação das responsabilidades do Estado para com seus cidadãos, delegando ao mercado ou ao chamado Terceiro Setor muitas daquelas funções prioritárias para superação da pobreza e da exclusão social. A estratégia baseada no empreendedorismo dos agentes e aquela fundamentada na forma do assistencialismo misericordioso representam, segundo Werneck Vianna (2007), os alicerces de uma nova concepção de política social que tenta substituir o papel que foi desempenhado pelo supostamente decrépito Estado de bem-estar com seu padrão universalista de proteção social.

Adicionalmente, a inclusão no mesmo pacote de setores da sociedade civil que lutaram pela democratização e as organizações civis vinculadas aos interesses empresariais levaram àquilo que Dagnino (2004) chamou de:

confluência perversa entre, de um lado, o projeto neoliberal que se instala em nossos países ao longo das últimas décadas e, de outro, um projeto democratizante, participatório, que emerge a partir das crises dos regimes autoritários e dos diferentes esforços nacionais de aprofundamento democrático" (Dagnino, op. cit., p. 195). ${ }^{6}$

Nesse sentido, o centro da questão não reside no falso dilema Estado versus sociedade civil, mas sim na percepção de como compatibilizar políticas estatais ativas de bem-estar social acompanhadas de participação, monitoramento e prestação de contas por parte das autoridades ante as demandas da cidadania.

\section{Tentativas de respostas perante o modelo de acumulação vigente}

Podemos afirmar que, no começo do século XXI, subsistem algumas das consequências mais visíveis do modelo de acumulação capitalista: desemprego e subemprego, informalidade, flexibilização, precarização ou falta de proteção no trabalho, concentração da renda, aumento da pobreza e exclusão social. A precarização do trabalho tem dado origem a um novo conceito-categoria que, segundo a acepção do sociólogo britânico Guy Standing, representaria a emergência de uma "nova classe social", definida por ele como o precariado. Essa novíssima classe social seria aquilo em que, atualmente, se encaixariam os migrantes, os jovens com ensino superior, mas com inserção precária no mundo laboral, e os filhos de operários tradicionais, que não conseguem emprego estável e bem remunerado e se resignam a ocupar postos de trabalho com menor status socioeconômico. ${ }^{7}$

Como contraponto dos impactos que tem a aplicação desse modelo sobre as populações regionais, em muitos países a preferência dos votantes permitiu a eleição na última década de um número importante de governos progressistas e, junto com isso, a convergência em torno da urgência de superar os efeitos deletérios herdados do neoliberalismo no âmbito econômico e social, impulsionando decididamente uma política que atenda às necessidades e aspirações do 
conjunto da população, sem exclusões.

Reforçando essa expectativa, no mais recente informe do Panorama Social deAmérica Latina elaborado pela CEPAL, constata-se que, em sua maioria, os países têm mantido um volume expressivo de recursos destinados a cobrir as necessidades sociais da população. Segundo esse organismo, a evolução recente do gasto público social indica que "a tendência de alocar maiores recursos públicos às políticas sociais se detém, mas não se reverte, o qual oferece garantias de financiamento, estabilidade e maior legitimidade institucional à política social" (CEPAL, 2013, p. 12).

Nesse contexto, em 2013, 28,2\% da população da América Latina era pobre, e a população em situação de pobreza extrema chegava a 11,3\% (Ver Gráfico 1). Isso significa que 164 milhões de pessoas são pobres, das quais 66 milhões são pobres extremos. Praticamente sem exceção, tem-se produzido na região uma queda da pobreza que, em média, alcança 15,7\% acumulados desde 2002. A pobreza extrema também registra uma redução apreciável de $8 \%$, ainda que seu ritmo de queda tenha sido lento nos anos recentes.

Com efeito, entre 2002 e 2008, o número de pessoas pobres reduziu-se a uma taxa anual de 3,8\% e o de pessoas em situação de pobreza extrema ao ritmo anual de $7,1 \%$. Contrariamente, entre 2008 e 2013 , a velocidade com que se reduziu o número de pessoas com ingressos insuficientes teve uma queda anual de $2,5 \%$ no caso da pobreza e de $0,9 \%$ quanto à extrema pobreza (CEPAL, 2013, p. 17).

\title{
Gráfico 1: Evolução da pobreza e extrema pobreza 1980-2013
}

\begin{abstract}
La pobreza se redujo en 2012, en 1,4 puntos porcentuales, y en 2013 se reduciría a un ritmo menor. A su vez, la pobreza extrema se mantiene sin cambios apreciables en ambos años. Para 2013 se estima que la pobreza se sitúe en el entorno del $28 \%$ y la pobreza extrema bajo el $12 \%$.
\end{abstract}

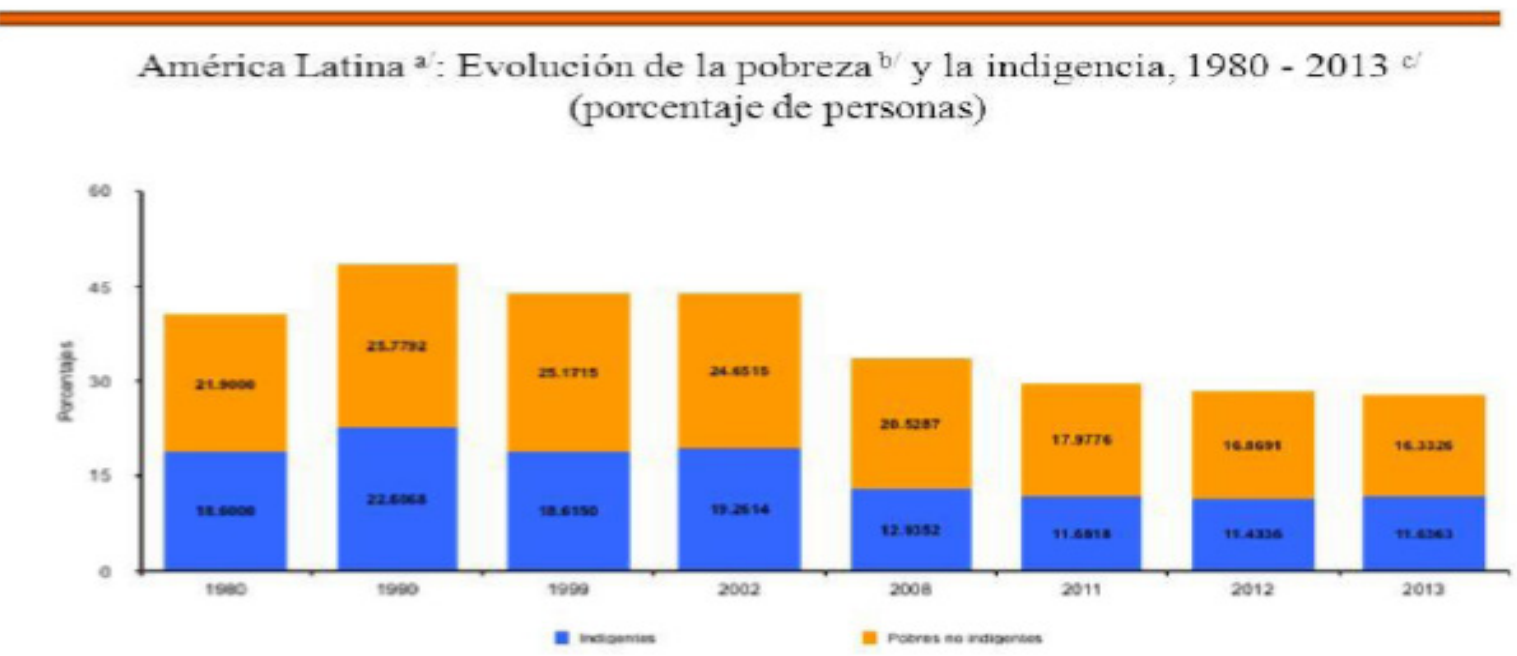

Fuente: CEPAL, sobela base detabulaciones especiales de las eneuestas de hogares de los respectivos paises Estimación correspondiente a 18 paises dela región más $\mathrm{H}$ aiti.

f C L P R Corresponde a la suma de indigentes más pobres no indigentes. E C L A R as cifias 2013 correspondea a una proyección. 
Com relação ao gasto público social, até meados da década de 2000, sua evolução foi altamente pró-cíclica. Na segunda metade da década, iniciaram-se vários países esforços sistemáticos para reforçar os programas sociais, em particular os dirigidos à luta contra a pobreza, fato que marcou o início da inflexão no comportamento do gasto social. Essa tendência já tinha se iniciado parcialmente em meados dos anos 1990 em países que se afastaram da visão mais ortodoxa a respeito das medidas de redução do gasto fiscal promovidas pelo Consenso de Washington (principalmente Brasil e o México).

Junto com o robustecimento de alguns grandes programas sociais (de luta contra a pobreza e de fortalecimento da proteção social, principalmente em seu pilar solidário ou não contributivo), somaram-se medidas de reorientação do gasto (e dos tributos) para evitar os efeitos regressivos do aumento dos preços dos produtos básicos, particularmente nos anos 2007 e 2008. Iniciada a crise financeira, os governos tomaram diversas medidas de estabilização da demanda interna, mediante o aumento do gasto público não social (investimento em infraestrutura) e, sobretudo, do gasto social. Dessa forma, a participação do gasto público social com relação ao Produto Interno Brasileiro (PIB) passou de $12,5 \%$ no período $1992 / 92$ para $19,2 \%$ no biênio 2010/11 (CEPAL, op. cit., pp. 39-40).

As cifras proporcionadas pela Cepal constatam o aumento do gasto social durante os últimos 20 anos e permitem vislumbrar que a situação de pobreza e indigência observada em quase todos os países não se tem modificado substancialmente. Os dados elaborados pela CEPAL são corroborados pelo Programa das Nações Unidas para o Desenvolvimento (PNUD), que anualmente mede o Índice de Desenvolvimento Humano
(IDH), o qual vai de 0 a 1. Esse índice se constrói fundamentalmente a partir de quatro indicadores: PIB per capita, expectativa de vida, taxa de alfabetização e taxa de matrícula bruta nos três níveis de ensino. Considerando os dados do relatório de 2013, com exceção do Chile e da Argentina, que figuram no lugar número 40 e 45 do ranking, respectivamente, o restante dos países da região se encontra numa posição baixa do IDH, especificamente o Brasil, que aparece em 85o. Segundo esse Informe, o país com pior desempenho no hemisfério é o Haiti, na posição número 161, com um Índice de Desenvolvimento Humano de somente 0,456 (PNUD, 2013).

De acordo com o que foi anteriormente apontado, surge de maneira quase inevitável a seguinte pergunta: "Se a maioria dos governos tem aumentado seus gastos sociais, por que os resultados na superação da pobreza continuam sendo limitados?". Diferentes argumentos se têm formulado para tentar dar resposta a esse aparente paradoxo. Uma primeira hipótese assinala que existem determinantes estruturais que impedem que os esforços realizados em termos de aumento do gasto social tenham impacto significativo entre os grupos carentes. Restrições patrimoniais, educacionais, demográficas, ocupacionais e de remunerações são levantadas como obstáculos para a obtenção de resultados com sucesso nos programas de superação da pobreza e no acesso aos serviços sociais. Além disso, os países devem lidar não somente com as diferenças de distribuição dos ingressos expressiva de suas estruturas econômicas, como também com a distribuição do gasto social na saúde, educação e seguridade social, uma vez que se realizam de forma desigual, favorecendo as camadas de maior renda. Com efeito, de acordo com algumas pesquisas, a distribuição dos gastos não tem sido feita de forma progressiva (quer dizer: 
maior gasto dirigido aos percentuais mais pobres), o que prejudica o acesso das famílias mais necessitadas aos benefícios sociais. ${ }^{8}$

Como segunda hipótese, sustenta-se que esses esforços continuam fortemente subordinados ao nível de desenvolvimento alcançado e, em muitos casos, associados às baixas cargas tributárias, o que torna insuficiente o volume de gasto público social em vários países da região. Além disso, a maioria dos governos continua sem aplicar as políticas contracíclicas, as quais não permitem gerar uma dinâmica de compensação de riscos sociais perante situações de contração na atividade econômica, reduzindo a capacidade pública de manter um sistema de proteção social para a população vulnerável.

Uma terceira hipótese é que as políticas sociais não têm tido a repercussão desejada devido ao tipo de gestão tradicional e à aplicação concreta que se realiza do gasto social, colocando ênfase às metas de execução do orçamento e à entrega de bens e/ou serviços a partir de parâmetros quantitativos (amplia cobertura), desestimando a importância de determinar, em primeiro lugar, a quantidade e a qualidade dos produtos que deveriam contemplar um programa social. Junto com isso, aspectos relativos à ausência ou debilidade na avaliação de impacto das ações e um seguimento permanente do gasto são considerados como fator que compromete a efetividade dos programas (Cohen, 2005).

\section{A relevância da dimensão política na políti- ca social}

Sem subestimar a validade dos motivos apontados, inclinamo-nos para uma interpretação diferente das anteriores. A nosso entender, um aspecto muito relevante e negligenciado nas análises precedentes tem relação com a dimensão política do problema em questão.
Noutras palavras, um aspecto crucial dessa problemática se encontra na ausência de conteúdo político da política social, quer dizer, o que está em debate é uma definição sobre qual é o lócus de "político" na construção de respostas à problemática social e à luta contra a pobreza e a exclusão. Esse desconhecimento da dimensão política concebe a solução da questão social como um exclusivo problema técnico de oferta de bens e serviços sociais a um grupo de "beneficiários". Por isso é que se fala em muitos casos de gerência social, tratando de incorporar os critérios empresariais à gestão dos programas sociais, como se o êxito deles dependesse da eficácia e eficiência na alocação do gasto. Os grupos "beneficiários" aparecem como entes passivos que devem ser objeto da política, o qual reduz em definitivo aos setores mais desprovidos da condição de meros receptáculos passivos dos programas sociais.

Há mais de 55 anos, Hannah Arendt (1958; 2005) nos advertia sobre os riscos da falta de distinção entre o espaço do social e o âmbito político. Para essa autora, a origem da confusão estaria na tradução latina do conceito aristotélico de zoon politikon como animal sociale, a qual incorpora uma atividade própria do espaço do lavour e familiar, que, por certo, é diferente do lugar da pólis, onde o homem trata desde os assuntos alheios aos estritamente privados e familiares, até passar a ocupar-se com questões que competem ao conjunto da comunidade que se congrega em torno de um território.

Nesse percurso, o propósito da filósofa alemã é, sobretudo, definir uma especificidade do político que o diferencia em particular do "social". Em síntese, a perspectiva arendtiana nos alerta sobre os perigos de misturar as duas esferas, pois, dessa 
maneira, o privado/doméstico pode irromper na esfera da política, estabelecendo-se um problemático acoplamento entre ambas e gerando, com isso, o domínio do político-social que termina subordinando e pervertendo a política (Garcia de la Huerta, 2003). O anterior nos pode levar a pensar erroneamente que os conflitos experimentados pelas sociedades modernas se extinguem com a simples solução da questão social, abdicando da dimensão política de todo o processo.

Se os recursos da política se eliminam na solução da problemática social e nos programas de superação da pobreza, a própria dimensão política, associada ao dito esforço, deixa de ter sentido. A solução do social passa a ser instrumental, uma questão de método, esvaziando-se em si mesma e depreciando seu caráter político. Em outras palavras, a questão social transformada no tema crucial leva o princípio da demanda mercantil à esfera pública, transforma-o em instância resolutiva sob a forma consolidada de gerenciamento social e prática administrativa.

A partir dessa concepção instrumental do social, o cidadão é percebido como um cliente da política, despojando-o de seu importante e imprescindível papel na construção do debate sobre os assuntos públicos. A dimensão política da sociedade confunde-se com a emergência da política social destinada a responder aos apelos da cidadania, demandas que estão circunscritas no âmbito das carências domésticas, privadas e familiares que enfrentam determinados setores da sociedade. Dessa forma, a política é deslocada para outro campo (das necessidades econômicas) resolvido através da intervenção social, sendo que sua função como "abertura do mundo e lugar de debate sobre questões fundamentais fica enclausurada, convertida em mero assunto de gestão e ge- rência, na simples administração das coisas" (Garcia de la Huerta, op. cit., p. 57).

Somada a essa redefinição do papel do Estado, com o processo de redemocratização iniciado na região a partir dos anos 1980, alçam-se vozes que, influenciadas pelas perspectivas funcionalistas, enfatizam o caráter harmônico e consensual da transição democrática. A própria Cepal, que foi palco importante no debate sobre o conflito social e econômico na realidade latino-americana, inaugura uma nova fase de seu pensamento com um posicionamento que estabelece uma espécie de renúncia a todos os postulados que marcaram sua reflexão nos anos 1940 e 1950. A ausência da temática do conflito aparece perigosamente nessas posteriores elaborações como forma de estabelecer a diferença.

Num documento dessa nova etapa, a Cepal (1990) conclui que, durante os anos 1980, a região passou por uma época de "aprendizagem dolorosa" e que, portanto, a experiência acumulada demonstraria que as divergências entre os diversos grupos deveriam ser superadas por meio de acordo e conciliação. Ou seja, no âmbito político-social, essa aprendizagem parece supor que o fim dos governos democráticos deveu-se fundamentalmente pelo fato de que as instituições foram abaladas pela irrupção de diversas demandas surgidas no universo social, as quais não puderam ser processadas pelo sistema político, dando lugar a crises de governabilidade e à consequente instauração das ditaduras militares. ${ }^{9}$

É muito provável que os governos e os múltiplos atores sociais e políticos que viveram a experiência "traumática" das ditaduras militares se sintam inclinados a adotar uma postura mais conciliadora e consensual a respeito do futuro de nossas sociedades e das formas de resolver as disputas políti- 
cas durante a denominada etapa da transição e consolidação democrática. Em outras palavras, considerando a situação dos países do hemisfério, é muito provável que certa desconfiança na práxis política e o escasso apreço pela participação cidadã tenham suas raízes no pesadelo autoritário sofrido por quase todos eles nesse período tenebroso da história contemporânea. Mas, ao contrário, a evidência empírica recopilada por diversos estudos continua demonstrando que a emergência de lutas sociais, as disputas pela prevalência de determinados interesses e, em suma, a existência dos conflitos fazem parte do cotidiano e da própria dinâmica observada em todas as sociedades, sem distinção.

Por tanto, como parâmetro teórico e referente histórico, compartilhamos a mesma visão daquela corrente das ciências sociais, ${ }^{10}$ que vê o conflito não como um agente desagregador da sociedade, mas sim como um fator inerente e parte indissolúvel das relações sociais, o qual, na maioria das vezes, contribui para o estabelecimento e consolidação dessas mesmas relações. Tal como foi salientado já faz algum tempo por Georg Simmel, o conflito está presente na relação entre indivíduo e sociedade na medida em que ela aspira ser uma totalidade e uma unidade orgânica, demandando que o indivíduo represente um papel e uma função determinada. Por sua parte, o indivíduo se revela contra a imposição desse papel: "ele que ser pleno em si mesmo, e não somente ajudar a sociedade a se tornar plena" (Simmel, 2006, p. 84).

Quer dizer, o conflito possui um caráter socializador à medida que estabelece um vínculo entre o indivíduo e a sociedade e estimula as relações sociais entre os diversos oponentes, sejam eles indivíduos ou coletividades. No seu devir, as partes desenvolvem regras de conduta e formas de expressão de suas divergências, num marco que estabelece limites sociais ao uso da violência extrema, evitando, dessa maneira, que tal violência seja aplicada com a finalidade de destruir moral, psicológica ou fisicamente ao contrário.

Nessa mesma linha, situa-se o enfoque "agonista","11 de Chantal Mouffe, quando manifesta que conceber o objetivo da política democrática em termos de consenso e reconciliação é conceitualmente errôneo e implica sérios riscos políticos.

A aspiração de um mundo, no qual se tenha superado a discriminação nós/eles, baseia-se em supostos falsos, e aqueles que compartilham essa visão estão destinados a perder de vista a verdadeira tarefa que enfrenta a política democrática: elaborar um projeto que reconheça o caráter ambivalente da sociabilidade humana e o fato de que reciprocidade e hostilidade não podem ser dissociadas (Mouffe, 2007, p. 13).

Dessa maneira, a arena política é o espaço de conflito por antonomásia, portanto o desafio da autoridade é reconhecer o desacordo intrínseco existente na sociedade e garantir as diferenças e possibilidades de que permanentemente se incorporem novas demandas na mesa de negociação.

Com efeito, a crença de que é possível alcançar um consenso racional universal tem empurrado o pensamento democrático para um caminho errôneo, já que só o reconhecimento de que é possível erradicar a dimensão conflitiva da vida social permitirá compreender o verdadeiro desafio da política democrática. Para isso, é preciso reconhecer a natureza conflitiva de nossas sociedades e aceitar que o papel a ser desempenhado pela ação política não consiste somente em superar essa confrontação por meio de um consenso apriorístico, mas, 
sobretudo, em reconhecer o confronto como parte indivisível da própria política democrática.

Essa forma equivocada de pensar a política democrática tem permeado a ação dos governos, o que, por sua vez, impossibilita que os atores políticos percebam a importância das mobilizações e dos movimentos sociais na construção democrática. Isso se reflete no apelo permanente da conservação da governabilidade, numa espécie de consagração da harmonia e reconciliação entre os homens, desconhecendo o importante papel que possa vir a desempenhar o conflito nas relações sociais e na própria dinâmica dos países. $O$ anterior é particularmente válido para o caso chileno, onde finalmente se impôs uma modalidade de conservadorismo sistêmico, político e moral com base no temor de qualquer forma de manifestação ou expressão de descontento que ameace desbordar o marco institucional. A nosso entender, a grande dificuldade que se desprende tanto da experiência chilena como a de outros países da região, consiste na tensão mal resolvida entre a participação democrática e a redução dos conflitos por meio de um apelo institucional para a manutenção da ordem e da inação social.

Muitos governos, que são declaradamente fiéis partidários do regime democrático, baseiam seus respectivos projetos em alianças intersetoriais que diminuem os conflitos para proporcionar continuidade tanto nos governos quanto nas estratégias de desenvolvimento. A redução de conflitos mediante a concertação social é fundamental mesmo como indicador de governabilidade e de redução do risco, condição para a possibilidade de receber capitais estrangeiros, assim como para fazer investimento interno do empresariado nacional. No entanto, a negação dos conflitos repercute numa despoli- tização e consequente redução da participação política. O governo comina à população, especialmente à juventude, que participe das eleições. Desaprovam-se a mobilização e a expressão de opiniões coletivas dissidentes, as que se vem - desde o governo - como escolhas para a "coesão social" pela que tanto se advoga (de la Cuadra, 2008).

Essa perspectiva que se retroalimenta, por sua vez, numa visão mercantil e asséptica da "questão social", recusa-se a reconhecer que existe um campo legítimo de disputas e conflitos que são parte constitutiva da ação política e, mais do que isso, da própria dinâmica social. Dessa forma, parece extemporânea a pretensão de algumas autoridades e alguns cientistas políticos de construir sociedades com base na ordem social e na artificial integração social amparada na gestão eficiente dos tecnocratas de turno, que tentam se antecipar e resolver as demandas dos cidadãos, onde finalmente a solução da problemática social passa pela administração eficiente dos recursos do Estado visando à execução de ações focalizadas que procuram atingir em primeira instância aqueles grupos com necessidades proeminentes.

Resumindo, pensamos que a principal preocupação de alguns governos latino-americanos, inclusive daqueles com o selo de progressistas (Argentina, Brasil, Chile, Equador, Bolívia ${ }^{12}$ ) parece orientar-se preferencialmente para o fortalecimento da governabilidade, estimulando os movimentos sociais a manter um baixo perfil em sua demanda ou ação contestatória ou cooptando-os por meio da máquina do governo. Diferentemente da noção conservadora, nesse caso, não existe nenhuma intenção explícita de limitar a expressão da dita demanda, pois agora se enfatiza o caráter "impróprio" que ela possui, em virtude da capacidade da autoridade de se antecipar às necessidades do povo e, des- 
sa forma, oferecer as soluções mais rápidas e adequadas a cada situação particular. Assim, tais governos estariam premunidos de equipes de experts e de um conjunto de estudos que permitiriam abordar com efetividade e eficiência as carências e dificuldades que atingem a população.

Finalmente, representa uma manifestação um tanto perversa da política das boas intenções. Parece que o caráter da inclusão democrática da cidadania se restringiria à sua credencial de "beneficiários" de programas sociais, em que a dimensão política dessa cidadania ficaria reduzida em seu apelo social e, por essa via, plenamente satisfeita. A participação democrática fica restrita à aceitação e legitimação da ordem institucional, em que o funcionamento das instituições democráticas formais representaria a garantia para a sustentação do sistema social.

\section{Reflexões finais}

A partir do que foi anteriormente exposto, surge a questão a respeito do paradigma positivista e gerencial do Estado, que incorpora as práticas para obter melhor desempenho. Além de ajudar a resolver os problemas sociais acumulados, as ações podem se transformar, simultaneamente, num fator de legitimidade para o conjunto do sistema político democrático de um país. Isso pode representar uma condição necessária, mas não suficiente para adquirir tal legitimidade, uma vez que deve ser produto de um processo bastante amplo de inclusão da cidadania no âmbito das deliberações e decisões sobre os assuntos de interesse público (res publica), que afetam a vida das pessoas e de suas comunidades de destino.

Ainda que nos discursos oficiais muitos governos reconheçam a importância da participação cidadã, em alguns casos ela é pouco estimulada. No papel, assinala-se que os cidadãos devem participar ativamente na execução dos diversos programas e projetos, em que os sistemas de controle e de prestação de contas das autoridades (accontability) representam um componente fundamental das democracias modernas, uma vez que não é possível construir democracia sem a ingerência dos cidadãos. Porém, em muitas oportunidades, os governos não têm desenhado fórmulas e canais consistentes para impulsionar a participação efetiva - que muitas vezes resulta inconveniente - das pessoas nas diversas arenas onde ela deve se expressar. Em certas ocasiões, a autoridade tem propiciado o desânimo por parte dos atores para representar seus interesses, baseando-se, para isso, na falsa concepção de que a participação é dispensável.

Entretanto, estamos cientes de que certos governos da região têm realizado esforços importantes para incorporar efetivamente o componente participativo nas políticas públicas em geral, e em particular em suas políticas sociais, onde participar significa em essência a possibilidade de a população assumir um papel ativo no processo decisório das políticas. Por exemplo, as experiências desenvolvidas especialmente pelos Municípios por meio do Orçamento Participativo, do Sistema Único de Saúde (SUS), com seus ConseIhos de Saúde Comunitária, os Conselhos de Segurança Alimentar (Consea) ou mais recentemente o Programa Territórios da Cidadania do Governo Federal -, demonstram que, no caso brasileiro, há ações de estímulo para a participação da população não somente na esfera consultiva e nos fóruns de discussão, mas também nos diversos âmbitos deliberativos (por exemplo: os Colegiados territoriais) e as respectivas arenas decisórias concernentes a cada po- 
lítica específica.

No entanto, é preciso advertir que esses espaços de "participação" também têm sido utilizados como manobra de cooptação, uma vez que a sociedade civil e os movimentos sociais passam a depender dos favores do governo para conseguir dar continuidade às suas demandas e às suas funções fiscalizadoras. A ação da União Nacional dos Estudantes (UNE) representa, a nosso entender, um caso emblemático de como as organizações sociais podem ser cooptadas pelo governo por meio de um conjunto de "benefícios" de transferência de recursos do Estado (para organizar eventos viagens etc.), com a finalidade de domesticar e disciplinar os principais atores do movimento e esvaziar de conteúdo suas demandas e possíveis mobilizações.

Contradizendo essa tendência de cooptação e controle da sociedade civil, diversos estudos realizados na região demonstraram nitidamente que a participação da população no desenho, na gestão e na avaliação dos programas sociais tem propiciado resultados muito superiores aos daqueles programas em que se impuseram ou implementaram de cima para baixo, com um critério hierárquico, vertical e burocrático (Cohen, 2005; Jarquín, 2000; Kliksberg, 2000).

Em síntese, sustentamos afirmativamente que aquilo que irá legitimar não só a política social efetiva mas também as instituições democráticas das nações latino-americanas é a possibilidade de que o conjunto dos cidadãos participe na construção de um modelo inclusivo de democracia direta, quer dizer, a partir do reconhecimento das diversas identidades políticas e seus decorrentes conflitos de interesses. A intenção é que todos os setores se sintam, finalmente, partícipes e pertencentes a uma comunidade política em que possam exercer sua capacidade delibe- rativa e decisória num contexto de equidade, pluralismo, tolerância e liberdade.

\section{Referências}

ARENDT, Hannah. (2005). A Condição Humana. Rio de Janeiro: Forense Universitária. , Versão em inglês. [1958]. The Human Condition, Chicago: The University of Chicago Press.

BRAGA, Ruy. (2012). A política do precariado: do populismo à hegemonia lulista. São Paulo: Boitempo Editorial.

CASTAÑEDA, Jorge. (2006). “Latin America's left turn". Foreign Affairs, maio/junho.

CEPAL. (2013). Panorama Social de América Latina, Santiago do Chile.

CEPAL. (2007). Panorama Social de América Latina, Santiago do Chile.

CEPAL. (1990). Transformación productiva con equidad: la tarea prioritaria del desarrollo para América Latina y el Caribe en los años 90, Santiago: Naciones Unidas.

COHEN, Ernesto. (2005). Los desafíos de las políticas y la gestión social en América Latina. Revista do Serviço Público. Brasília, vol. 56 , n. 4, pp. 403-417.

COUTINHO, Carlos Nelson. (2000). Prefácio. In: SEMERARO Giovanni, Gramsci e a sociedade civil. Petrópolis: Vozes.

CÚPULA IBERO-AMERICANA. Declaração do Panamá, no sítio da Secretaria Geral Ibero-Americana. Disponível em: <http://segib.org/sites/default/files/declaracao-XXIII-P. pdf>. Acesso em: 12 jun. 2014. 
DAGNINO, Evelina. (2004). Confluência perversa, deslocamento de sentido, crise discursiva. In: GRIMSON A. (compilador). La cultura en las crisis latinoamericanas. Buenos Aires: CLACSO.

DA SILVA, Fabricio. (2011). Vitórias na crise: trajetórias das esquerdas latino-americanas contemporâneas. Rio de Janeiro: Ponteio Edições.

DE LA CUADRA, Fernando. (2008). Conflito social e movimento estudantil no Chile. Estudos Históricos. Rio de Janeiro, vol. 21, n. 42, pp. 173-194.

FERNANDES, Rubem César. (2002). Privado, porém público: o terceiro setor na América Latina. 3a ed. Rio de Janeiro: Editorial Civicus.

FLEURY, Sonia. (2004). Construcción de ciudadanía en entornos de desigualdad. Revista Instituciones y Desarrollo. Barcelona, n. 16, pp. 133-170.

GARCIA DE LA HUERTA, Marcos. (2003). Pensar la política. Santiago: Editorial Sudamericana.

GARRETON, Manuel Antonio et al. (2007). América Latina no século XXI: em direção a uma nova matriz sociopolítica. Rio de Janeiro: Editora Fundação Getulio Vargas.

HARDY, Clarisa. (1996). Necesidades básicas y organización popular en Chile: de la Subsistencia Defensiva a la Creatividad Popular. Santiago: Programa de Economía del Trabajo (PET).

HUNTINGTON, Samuel P. (1968). Political Order in Changing Societies. New Haven: Yale
University Press.

JARQUÍN, Edmundo. (2000). Estado democrático y gobernabilidad en el siglo XXI. Revista Instituciones y Desarrollo, Barcelona, n. 6.

KLIKSBERG, Bernardo. (2000). ¿Cómo reformar el Estado para enfrentar los desafíos sociales del 2000?. Revista Instituciones y Desarrollo, Barcelona, n. 6.

MOUFFE, Chantal. (1996). O regresso do político. (Ana Cecília Simões, Trad.). Lisboa: Gradiva.

. (2007). En torno a lo político. México: Fondo de Cultura Económica.

PNUD. (2013). Informe sobre Desarrollo Humano. Nova York: Nações Unidas/PNUD.

SANT'ANNA, Julia. (2007). Governos de esquerda e o gasto social na América do Sul. Observador On-Line, vol. 2, n. 2, IUPERJ, Rio de Janeiro, pp. 1-20.

SIMMEL, Georg. (2006). Questões fundamentais da sociologia: indivíduo e sociedade. Rio de Janeiro: Jorge Zahar Editor.

STANDING, Guy. (2013). O precariado: a nova classe perigosa. (Cristina Antunes, Trad.). Belo Horizonte: Autêntica Editora.

UNICEF. (1986). Del Macetero al Potrero. El aporte de la sociedad civil a las políticas sociales. Santiago: Unicef/CPS.

WERNECK VIANNA, Maria Lúcia. (2007). Hiper-realidade ou hipoteoria? Política Democrática, Brasília, vol. VI, n. 19, pp. 55-63. 


\section{NOTAS}

1. Também chamada como Matriz Sociopolítica neoliberal por alguns especialistas. A noção e a perspectiva teórica atreladas ao conceito de matriz sociopolítica foram desenvolvidas e incorporadas, há uma década aproximadamente, ao léxico e ao meio acadêmico e está exposta de maneira sintética no trabalho de Garretón et al., 2007.

2. Afirmamos isso, sem entrar no mérito da discussão a respeito do que significa ser, na atualidade, socialista, de esquerda ou progressista no mundo e na América latina, o qual daria assunto para outro trabalho de maior fôlego. Existem, no entanto, diversas tipologias para caracterizar os governos de esquerda da região. Uma delas cria uma espécie de continuum entre os governos de esquerda que se alojam no modo renovador ou progressista e os governos que se localizam no polo "refundador" ou rupturista. Nesse último polo, o autor situa os governos de Cuba, Venezuela, Bolívia, Equador, Nicarágua e El Salvador. Entre os governos do eixo reformista se situariam os casos de Argentina, Brasil, Chile, Uruguai, Peru, Costa Rica (da Silva, 2011). Outro autor (Castañeda, 2006) distingue os diversos projetos a partir de uma tipologia dicotômica em que, por uma parte, estariam as administrações de esquerda consideradas modernas, reformistas, autocríticas, integradas, globalizadas (Chile, Brasil, Uruguai, Costa Rica) e, no outro polo, se situariam os governos da esquerda populista, anti-imperialista, fechada e nacionalista (Cuba, Venezuela, Bolívia, Equador e Argentina).

3. Por exemplo, pode-se recorrer à difundida frase de Rafael Correa, que afirmou em seu discurso no momento de assumir a presidência do Equador: "América Latina não está vivendo uma época de mudança, mas estamos vivendo uma mudança de época...."

4. Existe uma prolífica produção acadêmica e institucional sobre o papel desempenhado pelas organizações não governamentais em programas de superação da pobreza, especialmente no período em que imperavam os regimes cívico-militares na região. Entre outros, é possível consultar: Fernandes, 2002; Hardy, 1996; Unicef, 1986.

5. Exceção feita ao Chile que iniciou a aplicação de um vasto programa de cunho neoliberal, já nos anos 1970, sob o regime ditatorial do General Pinochet.

6. Esse aspecto já tinha sido salientado anteriormente por Coutinho, num artigo no qual postula que, no contexto da luta contra a ditadura militar, o conceito de sociedade civil tornou-se sinônimo de tudo aquilo que - com características virtuosas - se contrapunha ao perverso Estado ditatorial, o qual foi facilitado pelo fato de que, no Brasil (e também no resto da região), o termo "civil" significa o contrario de "militar" (Coutinho, 1999).

7. Na concepção de Standing, o precariado não representa somente um aspecto de emprego inseguro, de baixa remuneração e de duração limitada. A condição de precariado implica falta de horizonte e identidade ocupacional, numa ausência de sentido e projeção como sujeitos ativos na realidade laboral e social. Sobre essa questão, pode-se consultar Guy Standing, 2013 e, para o caso brasileiro, Ruy Braga, 2012.

8. Tal e como demonstra o citado informe da CEPAL ou a pesquisa realizada por Julia Sant'Anna (2007) como parte das atividades do Observatório Político Sul-Americano.

9. Ainda que não seja explicitada pela CEPAL, esse tipo de interpretação se nutre da noção de governabilidade sustentada por Samuel P. Huntington para quem afirma que a estabilidade política de um país se rompe quando não existe um marco institucional capaz de suportar o nível crescente de demandas dos atores sociais e políticos. Tal institucionalidade acaba sendo superada por setores ou grupos que irrompem com novas reivindicações no cenário nacional, levando ao colapso do sistema democrático. Dessa forma, o problema da governabilidade da democracia 
aponta para os limites que o sistema deve impor a seus cidadãos, para que os decorrentes "excessos" sejam devidamente controlados pela autoridade estatal (Huntington, 1968).

10. Referimos-nos a toda a tradição das Ciências Sociais que concebe a conformação das sociedades como espaços de contradições e conflitos permanentes, ainda que entre delas as resoluções para tais conflitos sejam diversas. Num caso, podemos atribuir uma relevância central à teoria de conflito de classes desenvolvida por Marx e Engels e continuada por toda uma fecunda produção e renovação dentro do pensamento marxista (Lenine, Trotsky, Mao, Gramsci, Poulantzas, Althusser etc.). Por outra parte, temos a teoria sociológica do conflito, iniciada pela reflexão de Simmel e continuada por Dahrendorf, Coser, Rex, Alexander. E finalmente, podemos mencionar a teoria da política democrática do conflito agonista desenvolvida principalmente por Chantal Mouffe e Ernesto Laclau.

11. O conceito agonista significa que o conflito não supõe necessariamente a existência de posturas antagônicas e irreconciliáveis, pois ainda que se reconheça a legitimidade da controvérsia, o "outro" é percebido como um adversário e não como um inimigo ao qual tem que se derrotar a qualquer custo. Daí surge o dualismo antagonismo/agonismo que pretende superar aquela concepção do conflito que remete necessariamente à destruição ou eliminação do outro. 12. No caso da Bolívia, por exemplo, as organizações dos povos originários, que habitam no Território Indígena e Parque Nacional Isiboro Sécure (TIPNIS) e se opuseram ao projeto da estrada transoceânica que atravessava seu território, foram duramente reprimidas pelas forças policiais durante a marcha que estavam realizando até a capital La Paz, para começar as negociações com o governo de Evo Morales. O principal argumento do governo, nesse momento, foi a manutenção da ordem e a segurança dos colonos e cocaleros (produtores de coca), que se assentaram recentemente no território em questão. 